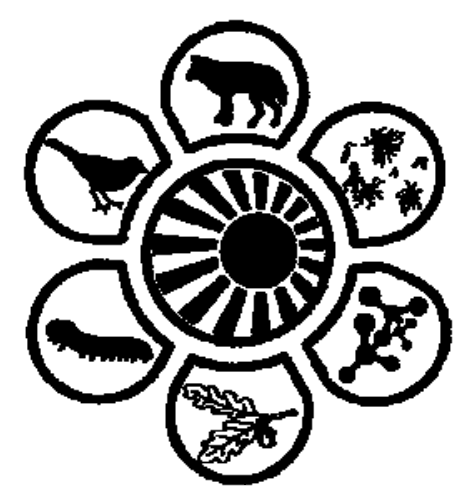

Вісник Дніпропетровського університету. Біологія, екологія. Vìsnik Dnìpropetrovs'kogo unìversitetu. Serîa Bìologîa, ekologìâ

Visnyk of Dnipropetrovsk University. Biology, ecology. 2013. 21(1)

ISSN 2310-0842

www.ecology.dp.ua

УДК 595.762.12

\title{
Оптимизация рациона Harpalus rufipes (Coleoptera, Carabidae) в условиях лабораторного содержания
}

\author{
Д.Е. Решетняк, В.В. Бригадиренко
}

Днепропетровский национальный университет имени Олеся Гончара, Днепропетровск, Украина

\begin{abstract}
Проанализирована методика лабораторного содержания жужелицы Harpalus rufipes (De Geer, 1774) - одного из важнейших вредителей зерновых культур. Имаго данного вида жужелиц содержали на преимущественно белковых, жировых и углеводных рационах. Отмечены значительные колебания потребления корма (отдельные экземпляры отказывались от потребления пищи). Особи со средней живой массой тела 148,2 \pm 45,6 мг потребляли в течение суток 71,4 \pm 99,4 и 77,2 $\pm 112,8$ мг свежемороженого куриного и свиного мяса (48,1\% и 52,1\% от массы тела в сутки соответственно). Сыр «Российский» и вареная колбаса потребляются в приблизительно таких же количествах (73,1 $\pm 81,3$ и 44,9 $\pm 66,0$ мг/сутки или 49,3\% и 30,3\% от массы тела). В значительно большем количестве потребляется вареное зерно пшеницы и гречихи $(103,5 \pm 108,5$ и $79,8 \pm 91,5$ мг или $69,9 \%$ и $53,9 \%$ от массы тела). В условиях отсутствия питания имаго H. rufipes (De Geer) ежесуточно теряло 2,6 $\pm 3,6$ мг живого веса (1,76\% от массы тела). Питание куриным, свиным мясом или вареной колбасой способствовало ежесуточному увеличению массы тела на $0,43-0,82$ мг $(0,29-0,56 \%$ от исходной массы тела). Значительно большее ежесуточное увеличение массы тела наблюдалось при питании сыром (3,14 $\pm 18,3$ мг/сут., $2,12 \%)$, пшеничными $(8,71 \pm 21,33$ мг/сут., 5,87\%) или гречневыми $(2,73 \pm 13,75$ мг/сут., $1,84 \%$ от массы тела) вареными зернами. При содержании в лабораторных условиях H. rufipes (De Geer) лучше содержать на смешанных рационах, содержащих вареное пшеничное зерно и сырое мясо свиньи или курицы.
\end{abstract}

Ключевые слова: Harpalus rufipes (De Geer, 1774); Carabidae; пищевые предпочтения; лабораторные эксперименты

\section{Optimizing of Harpalus rufipes (Coleoptera, Carabidae) diet under laboratory conditions}

\author{
D.Y. Reshetniak, V.V. Brygadyrenko
}

\section{Oles Honchar Dnipropetrovsk National University, Dnipropetrovsk, Ukraine}

Development of the laboratory breeding technology of insects that damage agricultural crops can help in the pest control. Harpalus rufipes (De Geer, 1774) were fed by the following types of products: fresh frozen chicken and pork, cooked sausage "Doctor", cheese "Russian", boiled wheat and buckwheat. In the experiment, 56 adult specimens were kept individually in plastic containers during five days. In the same conditions 8 control test products were placed to determine the percentage of its mass loss due to desiccation. Keeping in a laboratory and feeding of H. rufipes (De Geer) by common human food is possible. Throughout the experiment, there were considerable variations in the consumption of food between individuals. Specimens of an average weight of $148.2 \pm 45.6 \mathrm{mg}$ consumed daily $71.4 \pm 99.4 \mathrm{mg}$ of freshfrozen chicken and $77.2 \pm 112.8 \mathrm{mg}$ of the pork meat (48.1\% and $52.1 \%$ of the body weight, respectively). Cheese and sausage were consumed in approximately the same amounts (73.1 \pm 81.3 and $44.9 \pm 66.0 \mathrm{mg}$ daily, or $49.3 \%$ and $30.3 \%$ of the body weight, respectively). Low protein crop ration (wheat and buckwheat) provided the increase of the food intake (103.5 \pm 108.5 and $79.8 \pm 91.5 \mathrm{mg}$ or $69.9 \%$ and $53.9 \%$ of the body weight, respectively). Chicken, pork meat and sausage contributed the weight gain, which amounts to about $0.43-0.82 \mathrm{mg}$ $(0.29-0.56 \%$ of initial body weight). A significant increase in body weight was observed for specimens feed by cheese (the weight gain was $3.14 \pm 18.3 \mathrm{mg}, 2.12 \%)$, by wheat $(8.71 \pm 21.33 \mathrm{mg}, 5.87 \%)$, and buckwheat $(2.73 \pm 13.75 \mathrm{mg}, 1.84 \%$ of the body weight). Starving indi-

Днепропетровский национальный университет имени Олеся Гончара, пр. Гагарина, 72, Днепропетровск, 49010, Украина. Тел.: +38095-565-76-29, +38050-939-07-88. E-mail: reshetnyak.ufo@yandex.ru,brigad@ua.fm.

Oles Gonchar Dnipropetrovsk National University, Gagarin ave., 72, Dnipropetrovsk, 49010. Ukraine.

Tel.: +38095-565-76-29, +38050-939-07-88.E-mail:reshetnyak.ufo@yandex.ru,brigad@ua.fm.

(С Д.Е. Решетняк, В.В. Бригадиренко, 2013 
viduals of $H$. rufipes that had an access to drinking water lost $2.6 \pm 3.6 \mathrm{mg}$ of the wet weight daily $(1.76 \%$ of the body weight). That low rate of basal metabolism ensures the species survival during unfavourable parts of the seasons (summer drought, long autumn rains, etc.). Thus, the changes of body weights in imagoes of similar diets are evaluated. The sustainable keeping of $H$. rufipes (De Geer) culture in a laboratory needs the alternation of used food. That problem should be studied in details.

Keywords: Harpalus rufipes; Carabidae; food preferences; laboratory experiments

\section{Введение}

Биология Harpalus rufipes (De Geer, 1774) исследована в природных условиях довольно детально (Petrusenko and Petrusenko, 1973; Lindroth, 1985; Midtgaard, 1999; Porhajašova et al., 2009; Harrison and Gallandt, 2012). H. rufipes (De Geer) - жужелица волосистая - миксофитофаг, питающийся вредителями сельского хозяйства, также вредящий зерновым культурам. По данным C.H. Lindroth (1985), в условиях Скандинавских стран вид обычно встречается на культивируемых землях, пастбищах, в садах, на загрязненных территориях, в рудеральных сообществах. В странах Центральной и Восточной Европы перемещается на более влажные участки (в поймы рек, понижения с гигро- и мезофильными типами увлажнения). Жужелица волосистая имеет палеарктический ареал, занесена в Северную Америку (Dunn, 1981). В северной части ареала поколение развивается два года, в южной - один год. Имаго встречается с конца марта - апреля по конец сентября - октября. Яйцекладка происходит с начала мая по июль. При двухлетнем цикле развития зимуют личинки и имаго.

Исследование вредоносности данного вида проводилось на полях зерновых культур, в садах, на плантациях ягодных и овощных культур (Kutasi et al., 2004; Zhang et al., 1997). H. rufipes (De Geer) представляет интерес как энтомофаг, истребляющий вредителей (колорадского жука, клубеньковых долгоносиков и подгрызающих совок), и как фитофаг, повреждающий широкий спектр возделываемых человеком растений (Briggs, 1965; Hengeveld, 1980; Kromp, 1999; Purvis and Fadl, 2002). Локально вид может достигать очень высокой численности, иногда заполняя почвенные ловушки более чем на 30\% их высоты, что неизбежно приводит к обострению конкурентных отношений с другими видами данного семейства (Niemelä, 1993; Makarov and Matalin, 2009).

По данным разных авторов (Petrusenko and Petrusenko, 1973) вид питается зерновыми (пшеница, рожь, просо, ячмень, овес, рис, сорго, кукуруза, гречиха), зернобобовыми (горох, фасоль, соя, бобы), техническими (свекла, картофель, подсолнечник, арахис, горчица, рапс, чуфа, клещевина, тимьян, салат, конопля), овощными (томаты, морковь, лук, щавель, салат), лекарственными (желтушник, мак, шалфей, пижма, подорожник, стальник) и кормовыми (суданка, тимофеевка, вика, люпин, клевер, эспарцет, люцерна) культурами. Имеются указания на повреждение H. rufipes (De Geer) мякоти съедобных грибов (боровики, сыроежки), проростков ели, сосны, граба, клена, ясеня и генеративных органов 19 видов дикорастущих трав (злаки, лилейные, крапивные, гречишные, маревые, бобовые, сложноцветные) (Petrusenko and Petrusenko, 1973).

Питание жужелиц в лабораторных и естественных условиях различается не только шириной спектра возможных кормовых объектов, но и изменением их доступности при различных погодных условиях, в разное время суток. Разработка технологий лабораторного содержания жужелиц-миксофитофагов (Sharova, 1974) должна базироваться на наблюдениях в естественных экосистемах. К сожалению, на данный момент имеется лишь небольшое количество публикаций о спектре питания жужелиц-миксофитофагов (Traugott, 1998; Fawki and Toft, 2005; Sasakawa, 2009; Klimeš and Saska, 2010) и H. rufipes (De Geer), в частности (Monzo et al., 2011; Harrison and Gallandt, 2012). Имеются серьезные исследования особенностей пищевых предпочтений H. rufipes (De Geer) относительно семян различных видов травянистых растений (Hartke et al., 1998; Honek et al., 2003; White et al., 2007; Shearin et al., 2008; Saska et al., 2010).

Разработка технологии лабораторного разведения насекомых, повреждающих посевы сельскохозяйственных культур, необходима для борьбы с вредителями. В последние годы она приобретает все большее значение. Все шире применяются синтетические и полусинтетические питательные среды. Основная задача массового разведения - получение максимального количества насекомых, отвечающих определенным биотехнологическим требованиям, при минимальных затратах и в наиболее короткий срок. Лабораторное содержание H. rufipes (De Geer) сопряжено со значительными затратами времени на сбор беспозвоночных - кормовых объектов в природных условиях (Brygadyrenko and Sokolov, 2007). В связи с этим разработка оптимальной технологии лабораторного содержания - необходимое условие минимизации негативного и оценки позитивного воздействия вида на культивируемые человеком культуры.

Цель данной работы - оценить возможности содержания H. rufipes (De Geer) в лабораторных условиях на разных типах рационов растительного и животного происхождения.

\section{Материал и методы исследований}

H. rufipes (De Geer) с использованием почвенных ловушек без фиксатора собирали в окрестностях г. Днепропетровск в июле 2012 года на обрабатываемых полях ячменя обыкновенного и кукурузы сахарной. Рацион H. rufipes (De Geer) исследовали в лаборатории кафедры зоологии и экологии Днепропетровского национального университета им. Олеся Гончара. Массу определяли на лабораторных аналитических весах JD-100 (точность 1 мг). Перед началом эксперимента все экземпляры жужелиц содержали в одном общем садке (им был обеспечен свободный доступ к воде и различным кормам животного и растительного происхождения).

Для кормления H. rufipes (De Geer) использовали следующие виды пищевых продуктов: свежемороженое куриное и свиное мясо, колбаса вареная «Докторская» (13\% белка, 22\% жира), сыр твердый «Российский» (29\% белка, 23\% жира), пшеничная (сечка, 10 мин. кипячения, 60\% влажности) и гречневая крупа (цельные 
лущеные зерна, 30 с кипячения, 60\% влажности). В ходе эксперимента 56 экземпляров имаго содержали индивидуально в пластиковых контейнерах $(8 \times 12$ см) при температуре $+22 \ldots+28{ }^{\circ} \mathrm{C}$ и относительной влажности воздуха 38-54\%. В таких же условиях размещали по 8 контрольных навесок исследуемых продуктов для установления процента $(D)$ изменения их массы в результате усыхания (David, 1998). Изменение массы корма в контроле составляло для продуктов животного происхождения 2-6\% в сутки (рис. 1), для пшеничной и гречневой каши $-10-15 \%$.

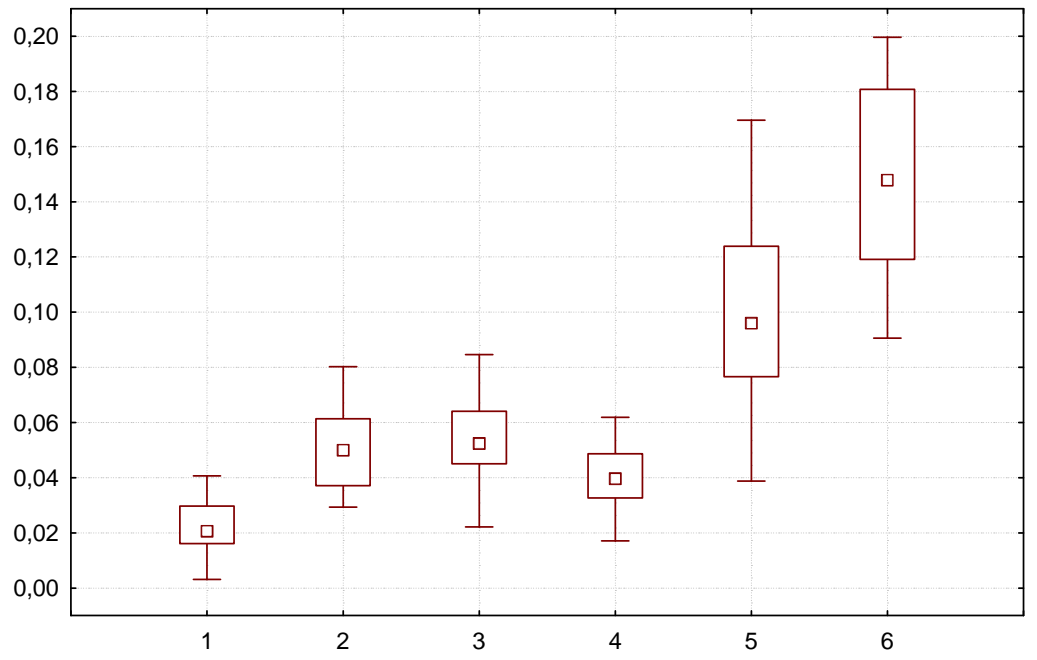

Рис. 1. Среднесуточное уменьшение массы пищи H. rufipes (De Geer) в условиях эксперимента: по оси абсцисс показаны варианты эксперимента 1 - куриное и 2 - свиное мясо, 3 - колбаса вареная, 4 - сыр «Российский», 5 - пшеничная и 6 - гречневая каша; по оси ординат - значение коэффициента $D$, $n=40$ для каждого варианта рациона

Опыт с каждым экземпляром H. rufipes (De Geer) проводили в течение пяти суток (ежедневно определяли массу потребленного корма, массу имаго, массу навески корма). Навеску корма ежедневно обновляли. Контрольная группа (8 экз.) какого-либо корма не получала в течение всего эксперимента. В садках контрольной и опытных групп вода для питья жуков была в свободном доступе. Обработку данных проводили в пакете программ Statistica 8.0. Достоверность отличий между выборками оценивали с помощью однофакторного дисперсионного анализа. В тексте данные представлены в виде $M \pm m$, на диаграммах отражены медиана, верхний и нижний квартили и диапазон колебаний.

\section{Результаты и их обсуждение}

Суточное потребление корма $H$. rufipes (De Geer) в условиях лабораторного эксперимента колебалось в значительных пределах даже при однотипном рационе жуков (рис. 2). Распределение значений суточного потребления корма достоверно отличалось от нормального (отмечались достоверные положительные и отрицательные значения асимметрии). Отдельные экземпляры жуков не питались или почти не питались на протяжении одних или двух суток. Неравномерное потребление корма на протяжении эксперимента характерно для многих беспозвоночных животных, в естественных условиях нерегулярно получающих доступ к пищевым ресурсам.

В течение суток имаго H. rufipes (De Geer) потребили $71,4 \pm 99,4$ и 77,2 $\pm 112,8$ мг свежемороженого куриного и свиного мяса, что составляет около половины массы их тела (48,1\% и 52,1\%, соответственно). Твердый сыр и вареная колбаса потреблялись приблизительно в таких же количествах $-73,1 \pm 81,3$ и 44,9 $\pm 66,0$ мг/сутки (относительно массы тела - 49,3\% и 30,3\%). Таким образом, на протяжении суток имаго H. rufipes (De Geer) потребляет корма средней массой 30,3-52,1\% от собственной массы тела. В начале и конце пятисуточного эксперимента для однотипных рационов достоверного изменения интенсивности потребления корма не отмечалось $(P>0,05)$.

Низкобелковые рационы из растительных продуктов (пшеница и гречиха) вели к увеличению потребления корма $(103,5 \pm 108,5$ и 79,8 \pm 91,5 мг или $69,9 \%$ и 53,9\% массы тела, соответственно). Неразмоченные пшеничные зерна и семена гречихи потребляются значительно хуже. Интенсивно поедаются замоченные жизнеспособные семена пшеницы и гречихи. В лабораторных условиях нами отмечены значительно более низкие темпы потребления вегетативных частей проростков указанных культур, чем прорастающих семян. В полевых условиях падалица пшеницы и гречихи является значительным компонентом рациона H.rufipes (De Geer) в летнеосенний период.

Несмотря на среднее потребление корма 44,9-103,5 мг для разных компонентов рациона, средняя суточная прибавка массы тела составила лишь 0,4-8,7 мг (рис. 3). То есть жуки увеличивали собственную массу тела не более чем на 9\% массы потребленного корма, значительную порцию энергии тратя на дыхание и экскрецию. Питание куриным, свиным мясом или колбасой способствовало ежесуточному увеличению массы тела на 0,43 0,82 мг (0,29-0,56\% массы тела). Значительно большее увеличение массы тела наблюдалось при питании сыром $3,14 \pm 18,3$ мг (2,12\%), пшеничной $(8,71 \pm 21,33$ мг/сут., $5,87 \%)$ или гречневой кашей $(2,73 \pm 13,75$ мг/сут., $1,84 \%$ массы тела). 


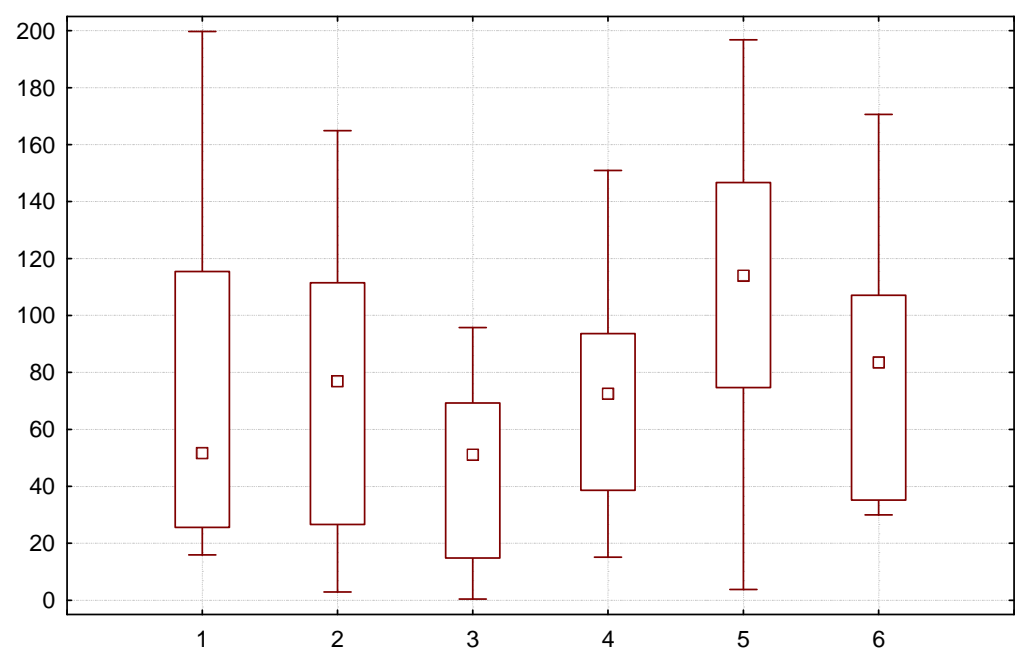

Рис. 2. Среднесуточное потребление пищи H. rufipes (De Geer) в условиях лабораторного эксперимента: по оси абсцисс показаны варианты эксперимента 1 - куриное и 2 - свиное мясо, 3 - колбаса вареная,

4 - сыр «Российский», 5 - пшеничная и 6 - гречневая каша; по оси ординат - суточное потребление пищи одним экземпляром имаго (мг), $n=40$ для каждого варианта рациона

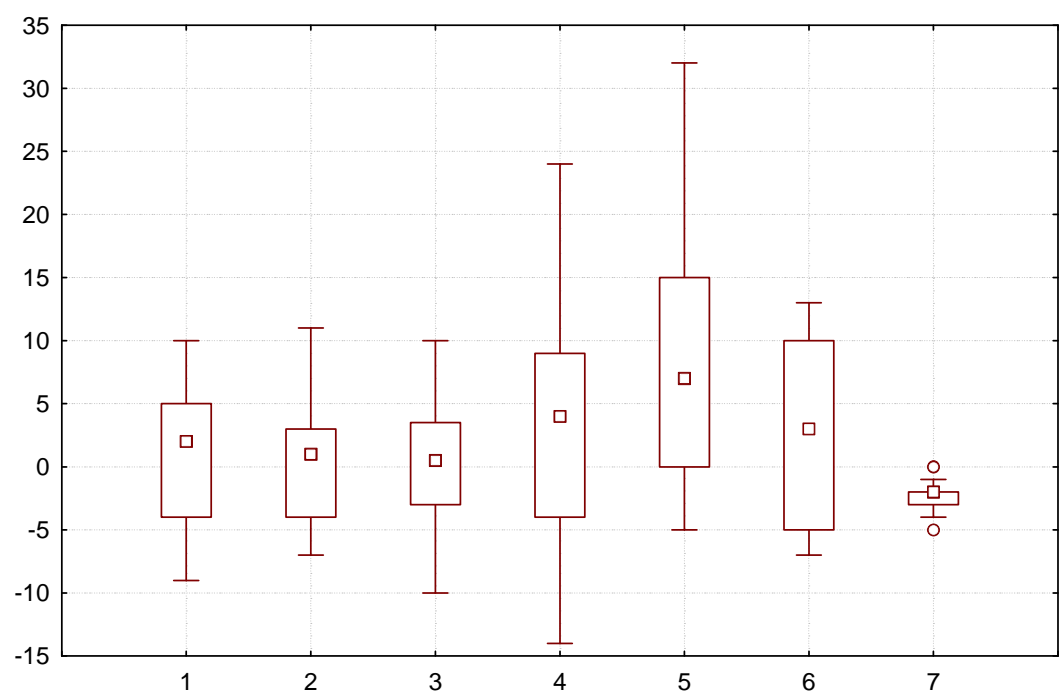

Рис. 3. Изменение массы тела H. rufipes (De Geer) на протяжени суток в условиях лабораторного эксперимента: по оси абсцисс - варианты кормления жужелиц (1 - куриное и 2 - свиное мясо, 3 - колбаса вареная,

4 - сыр «Российский», 5 - пшеничная и 6 - гречневая каша, 7 - отсутствие корма), по оси ординат - изменение массы тела (мг; средняя масса тела особей в эксперименте -

$148,2 \pm 45,6$ мг, 56 экз. по 5 взвешиваний)

Голодающие экземпляры H. rufipes (De Geer) при наличии доступа к свежей воде для питья ежесуточно теряли по 2,6 $\pm 3,6$ мг (1,76\% массы тела). Это очень низкий показатель основного обмена, обеспечивающий выживание вида в неблагоприятные для активности периоды сезона (летние засухи, периоды затяжных осенних дождей и др.). Разработка лабораторных рационов H. rufipes (De Geer) требует дальнейших исследований. Исходя из полученных результатов, необходимо оценить влияние рациона на массу тела жуков для более длительных (продолжительностью более 20 суток) и разнообразных по набору кормов (беспозвоночные животные, плоды и вегетативные органы зерновых, технических, масличных, овощных, плодовых, ягодных культур, адвентивных, сорных растений и местной дикорастущей флоры) экспериментов.

\section{Выводы}

Лабораторное содержание H. rufipes (De Geer) возможно при питании наиболее распространенными пищевыми продуктами человека. Наблюдались значительные колебания потребления корма у отдельных экземпляров на протяжении эксперимента. Особи средней массой $148,2 \pm 45,6$ мг потребляли в течение суток 71,4 \pm 99,4 и 77,2 $\pm 112,8$ мг свежемороженого куриного и свиного мяса $(48,1 \%$ и $52,1 \%$ от массы тела в сутки, соответственно). Сыр и колбаса потреблялись в приблизительно таких же количествах $(73,1 \pm 81,3$ и 44,9 $\pm 66,0$ мг/сутки или 49,3\% и 30,3\% от массы тела). Низкобелковые рационы из растительных продуктов (пшеница и гречиха) вели к увеличению потребления корма $(103,5 \pm$ 
108,5 и 79,8 $\pm 91,5$ мг или $69,9 \%$ и 53,9\% от массы тела). Голодающие экземпляры H. rufipes (De Geer) при наличии доступа к свежей воде для питья ежесуточно теряли по 2,6 \pm 3,6 мг живого веса (1,76\% массы тела). Питание куриным, свиным мясом или колбасой способствовало ежесуточному увеличению массы тела на 0,43-0,82 мг $(0,29-0,56 \%$ исходной массы). Значительно большее увеличение массы тела наблюдалось при питании сыром $3,14 \pm 18,3$ мг (2,12\%), пшеничной $(8,71 \pm 21,33$ мг/сут., $5,87 \%)$ или гречневой кашей $(2,73 \pm 13,75$ мг/сут., $1,84 \%$ массы).

В проведенных экспериментах оценено изменение массы тела имаго при однотипных рационах, однако для устойчивого содержания лабораторной культуры H. rufipes (De Geer) необходимо чередование наиболее употребляемых продуктов во времени. Данный вопрос нуждается в дальнейшем детальном исследовании.

\section{Библиографические ссылки}

Briggs, J.B., 1965. Biology of some ground beetles (Coleoptera, Carabidae) injurious to strawberries. Bull. Entomol. Res. 56(1), 79-93.

Brygadyrenko, V.V., Sokolov, S.V., 2007. Osoblyvosti spektru zhyvlennja Harpalus rufipes (Coleoptera, Carabidae) u laboratornyh umovah [Features of Harpalus rufipes (Coleoptera, Carabidae) feeding spectrum in the laboratory condition] Bioriznomanittja ta Rol' Tvaryn v Ekosystemah: Materialy IV Mizhnarodnoi' naukovoi' konferencii'. Dnipropetrovsk, DNU, 241-242.

David, J.-F., 1998. How to calculate leaf litter consumption by saprophagous macrofauna? Eur. J. Soil Biol. 34, 111-115.

Dunn, G.A., 1981. Distribution of Harpalus rufipes De Geer in Canada and United States (Coleoptera: Carabidae). Entomol. News 92(5), 186-188.

Fawki, S., Toft, S., 2005. Food preferences and the value of animal food for the carabid beetle Amara similata (Gyll.) (Col., Carabidae). J. Appl. Entomol. 129(9-10), 551-556.

Harrison, S., Gallandt, E.R., 2012. Behavioural studies of Harpalus rufipes De Geer: An important weed seed predator in Northeastern US agroecosystems. Int. J. Ecol. DOI: $10.1155 / 2012 / 846546$

Hartke, A., Drummond, F.A., Liebman, M., 1998. Seed feeding, seed caching, and burrowing behaviors of Harpalus rufipes De Geer larvae (Coleoptera: Carabidae) in the maine potato agroecosystem. Biol. Control 13(2), 91-100.

Hengeveld, R., 1980. Qualitative and quantitative aspects of the food of ground beetles (Coleoptera, Carabidae): A review. Neth. J. Zool. 30(4), 555-563.

Honek, A., Martinkova, Z., Jarosik, V., 2003. Ground beetles (Carabidae) as seed predators. Eur. J. Entomol. 100(4), 531-544.

Klimeš, P., Saska, P., 2010. Larval and adult seed consumption affected by the degree of food specialization in Amara (Coleoptera: Carabidae). J. Appl. Entomol. 134(8), 659-666.

Kromp, B., 1999. Carabid beetles in sustainable agriculture: A review on pest control efficacy, cultivation impacts and enhancement. Agric. Ecosyst. Environ. 74(1-3), 187-228.

Kutasi, C., Markó, V., Balog, A., 2004. Species composition of carabid (Coleoptera: Carabidae) communities in apple and pear orchards in Hungary. Acta Phytopathol. Hun. 39(1-3), $71-89$.

Lindroth, C.H., 1985. The Carabidae (Coleoptera) of Fennoscandia and Denmark. No. 1. Brill Academic Pub.

Makarov, K.V., Matalin, A.V., 2009. Lokal'naja fauna zhuzhelic (Coleoptera, Carabidae) kak ob'ekt izuchenija (na primere ka-rabidofauny Prijelton'ja) [Local fauna of ground beetles (Coleoptera, Carabidae) as object of study (for example, fauna of ground beetles of Prieltonye)]. Vidy $\mathrm{i}$ Soobshhestva v Jekstremal'nyh Uslovijah [Species and Communities in Extreme Conditions]. Moskow-Sofia, KMK, Pensoft, 353-374.

Midtgaard, F., 1999. Is dispersal density-dependent in carabid beetles? A field experiment with Harpalus rufipes (Degeer) and Pterostichus niger (Schaller) (Col., Carabidae). J. Appl. Entomol. 123(1), 9-12.

Monzó, C., Sabater-Muñoz, B., Urbaneja, A., Castañera, P., 2011. The ground beetle Pseudophonus rufipes revealed as predator of Ceratitis capitata in citrus orchards. Biol. Control 56(1), 17-21.

Niemelä, J., 1993. Interspecific competition in ground-beetle assemblages (Carabidae): What have we learned? Oikos 66(2), 325-335.

Petrusenko, A.A., Petrusenko, S.V., 1973. Semejstvo zhuzhelicy (Carabidae) [The family of ground beetles (Carabidae)] In: Vasil'ev, V.P. (Ed.). Vrediteli Sel'skohozjajstvennyh Kul'tur i Lesnyh Nasazhdenij [Pests of Agricultural Crops and Forest Plantations]. Kiev, Urozhaj. 1, 363-387.

Porhajašova, J., Petřvalsky, V., Macak, M., Urminska, J., 2009. Occurrence of species family Carabidae (Coleoptera) indepence on the input of organic matter into soil. J. Cent. Eur. Agr. 9(3), 557-565.

Purvis, G., Fadl, A., 2002. The influence of cropping rotations and soil cultivation practice on the population ecology of carabids (Coleoptera: Carabidae) in arable land. Pedobiologia 46(5), 452-474.

Sasakawa, K., 2009. Diet affects male gonad maturation, female fecundity, and larval development in the granivorous ground beetle Anisodactylus punctatipennis. Ecol. Entomol. 34(3), 406-411.

Saska, P., Martinkova, Z., Honek, A., 2010. Temperature and rate of seed consumption by ground beetles (Carabidae). Biol. Control 52(2), 91-95.

Sharova, I.H., 1974. Zhiznennye formy imago zhuzhelic (Coleoptera, Carabidae) [Life forms of adult beetles (Coleoptera, Carabidae)]. Zoologicheskij Zhurnal 53(5), 692-709.

Shearin, A.F., Reberg-Horton, S.C., Gallandt, E.R., 2008. Cover crop effects on the activity-density of the weed seed predator Harpalus rufipes (Coleoptera: Carabidae). Weed Sci. 56(3), 442-450.

Traugott, M., 1998. Larval and adult species composition, phenology and life cycles of carabid beetles (Coleoptera: Carabidae) in an organic potato field. Eur. J. Soil Biol. 34(4), 189-197.

White, S.S., Renner, K.A., Menalled, F.D., Landis, D.A., 2007. Feeding preferences of weed seed predators and effect on weed emergence. Weed Sci. 55(6), 606-612.

Zhang, J., Drummond, F.A., Liebman, M., Hartke, A., 1997. Phenology and dispersal of Harpalus rufipes DeGeer (Coleoptera: Carabidae) in agroecosystems in Maine. J. Agr. Urban Entomol. 14(2), 171-186. 